\title{
Academic Performance of Physical Therapy Graduates in the Licensure Examination
}

\author{
EDRALYNE SETH B. BESA \\ edralyne@gmail.com \\ ORCID No: 0000-0001-8983-8085
}

\begin{abstract}
The academic performance of the Physical Therapy graduates refers the Grade Percentage Average of The Physical Therapy graduates from all their accumulated major subjects into three groups and their subsequent Licensure Examination results in three the same groups, as well. This study explores the relationship between the Licensure exam scores and the academic performance of the graduates of the same groups. The study used documentary analysis on the existing school records as to the GPA of the three groups on the graduates from 1999-2012 and the ratings of the same groups from the Professional Regulations Commission. It made use of frequencies, percentages, correlation, and analysis of variance of the Licensure Examination Results and Academic Performance (GPA) on the three groups. Results showed that among the three groups, the Physical Therapy Applications group has the highest mortality rate. Majority obtained Fair (GPA of 2.6-3.0) in their academic performance; these are not predictors of passing the Licensure Examinations. The outcome of this study is one of the bases for the curricular review of the courses and programs of the Physical Therapy Department of the University of Bohol.
\end{abstract}

\section{KEYWORDS}

Academic Performance, Grade Percentage Average, ANOVA, Asia, Philippines 


\section{INTRODUCTION}

Physical Therapy (PT) has now become a popular college course to take in the Philippines today. Ohtake PJ. (2010) defines PT as a health care profession that aims to assist individuals with the achievement, maintenance, and restoration of maximal physical functioning and health throughout their life. It participates with another team as professional who are autonomous practitioners with expertise in movement science. Physical Therapy services are provided by licensed physical therapists.

US News \& World Report has repeatedly included physical therapists among its best 100 jobs in terms of employment opportunity, good salary, manageable work-life balance, and job security: 2014 (\#7), 2013, 2012 and 2009. CNNMoney. com also included physical therapists among its list of the top 10 "Fastest Growing Jobs" in November 2012 and ranked the profession \#4 out of 200 "Best Jobs in America" in 2010.

There is a high demand for physical therapists in the workforce. According to the American Bureau of Labor Statistics, employment of physical therapists is expected to grow by 39 percent from 2010 to 2020, much faster than the average for all occupations. The need for PT is expected to increase into foreseeable future as the U.S. population ages and the demand for PT services grows. The researcher expects, therefore, that there will be an increase in the number of students enrolling in PT education program.

The licensure examination for the practice of physical therapy in the Philippines consists of written examination on the scope which shall be determined by the Board of Examiners, taking into consideration the teaching plan of the schools legally constituted in the Philippines. In order to pass the first examination, a candidate must obtain a general rating of not below seventy-five percent in the written examination with no rating below sixty percent.

In line with the vision-mission of the University of Bohol (UB) being the premier University that enables a person to live worthy, fulfilling and abundant life the PT Department of University of Bohol started its operation in June 1994, the first academic institution to offer a Bachelor's Degree in Physical Therapy in the province.

However, through the records of the Physical Therapy and Occupational Therapy department there were fluctuations in the enrollment due to the rise and fall of the demand in the labor market. On the same hand, the passing percentage also fluctuated. The trending of this passing percentage is monitored by the PT department, however, an in-depth factorial analysis on the rate of 
failure problem such as: the subject section that generated the lowest passing rate and the causative factors behind were not thoroughly studied.

As to the theoretical perspective utilized in this study, it anchors on the behavioral learning theory. As defined by Burns 1995 learning is a relatively permanent change in behavior, and behavior covers both the tangible and intangible processes such as thinking, attitudes and emotions. In this definition, Burns pointed out that motivation is included in the whole process. He placed into consideration that learning may not be manifested for a time after the educational program has taken place. Sawkut 2010 added,

"learning is not the end; it is a process through which an individual increases his stock of knowledge and uses that knowledge to adapt into new environments and in defining a set of principles that he uses in his life."

According to Bower \& Hilgard 1981, the prominence of the laws of association propagated by Aristotle in the 1900s was expanded by the work of Edward L. Thorndike, the renowned proponent of learning theory that influenced all others in America for almost half a century). Thorndike plotted the learning curve of animals which he anchored of several puzzle box experiments. Through this study on Animal Intelligence (Thorndike 1898), learning definition was coined as the amount of time needed for an animal to get away from the box (Weibell, 2011).

As Thorndike1998 pointed out, the formed association could not have previously been experienced or covered by the ordinary occurrences in the life of ordinary animals. This further defines the connection of a particular situation and resultant pleasure.

The law of readiness states that when an animal is ready to conduct (respond), the process of undergoing such act is satisfying, and not to conduct or respond is annoying, when one is forced to do the act leads to annoyance (Thorndike 1998).

The law of exercise expounds that the more the connection between the stimulus and response is activated, the stronger it becomes. The law of effect addresses the pleasure that one gets from successful learning, thus, increasing the probability of future attempts (Schell 2000).

The researcher undertook this study to assess the performance of the PT Licensure examinations among its graduates from 1999-2012 as an institutional basis for curriculum review. Results would serve as important feedback 
mechanism to the department for programmatic improvement of the curriculum, thus, increasing the licensure passing rate among its graduates.

Specifically, this sought to answer the following questions:

1. What is the result of the licensure examination among the PT graduates?

2. What is the GPA and licensure results of the following subjects:

2.1 Anatomy, Physiology and Kinesiology

2.2 Medical and Surgical Conditions

2.3 Physical Therapy Applications

3. Is there a significant correlation between the GPA of the following subject sections: 1) Anatomy, Physiology and Kinesiology, 2) Medical and Surgical Conditions, and 3) PT Applications and the results of the licensure examinations in the same subject sections.

The purpose of this investigation was to determine if the student's performance (GPA) in the three major subjects is a predictor in passing the licensure exam. Also, as to which subject that graduates had the highest difficulty in passing.

A study conducted by Vendrely 2007 yielded to a significant relationship between the California Critical Thinking Skills Test (CCTST) and GPA and success on the NPTE. Thieman, Weddle and Moore (2003) used admission criteria, Clinical Performance Instrument scores and GPA to predict National Physical Therapy Examination (NPTE) success among post-baccalaureate professional PT students. The researchers found that pre-admission (undergraduate) GPA, graduate record examination (GRE) scores and age predicted graduate GPA. Only pre-admission GPA was statistically related to NPTE scores. Like previous studies, the relationship was found between GPA and NPTE success.

Likewise, a similar study was conducted by Stewart C, Bates RE, Jr. Smith GE (2005) the relationship between performance in dental school and performance on a dental licensure examination. Significant relationship was noted according to graduating GPA, and the overall performance on the Florida dental licensure exam. According to Stewart C, et.al (2005), an analysis of failures on exam sections resulted in the discovery that the manikin portion was associated with the highest failure rate. The results provide an opportunity to improve licensure exam performance of future graduates through additional instruction and practice. 
Daley, Kirkpatrick, Frazier, Chung, and Moser (2003) concluded in their study that cumulative GPA were found to be significantly different in students who were successful on the NCLEX-RN and those who were not. These findings are similar to many prior studies that found higher grades in nursing courses to be predictive of NCLEX-RN success.

On the other hand, Julian, E (2005) studied the validity of the Medical College Admission Test (MCAT) for predicting medical school performance. It investigates the extent to which MCAT scores supplements the power of undergraduate grade point average (uGPA) to predict success in medical school. The result was that grades were best predicted by a combination of MCAT scores and UGPA. However, MCAT scores were better predictors of United States Medical Licensing Examination (USMLE) step scores than were uGPAs but a combination did little better than MCAT scores alone.

Although these above studies were allied to this study, this is different in the sense that it sought to find out whether there is a significant correlation between GPA and the results of the licensure examination in the three-board subjects; hence, the research gap which this study seeks to fill.

\section{METHODOLOGY}

This study is descriptive in nature and utilized as well a documentary analysis of existing records from the Registrar's Office pertaining to the General Passing Average (GPA) of the three board subject components and the ratings of the licensure examination of the Professional Regulation Commission (PRC). The coverage of the study is from August 1999 - August 2012, except for March 2008 and 2010 graduates because no one took the board examination on those years.

The researcher made a classification of the academic performance in the three Board subjects namely: (1) Anatomy, Physiology and Kinesiology; (2) Medical and Surgical Conditions, and (3) Physical Therapy Applications. These are compared to their GPA according to the three areas and their performance in the Physical Therapy Licensure Examination in the said three Board subject areas.

The data of the above mentioned variables were obtained from the Professional Regulations Commission's result insofar on the performance in Licensure examinations was concerned whereas their academic performance was from the Registrar's Office of the University of Bohol. Both of these were done through analysis of existing documents. The data from these variables are herein presented under different problems of the study. 
Likewise, the UB Registrar released the GPA of graduates who took the subsequent licensure exam for Physical Therapists. The GPA were ranked as Excellent (1.0 - 1.5), Very Good (1.6 - 2.0), Good (2.1 - 2.5), Fair (2.6 - 3.0) and Poor (above 3.0). This ranking was based upon the grading system of the College of Physical Therapy.

The data were then collated, analyzed and interpreted using percentile and Pearson Product Moment Coefficient Correlation formula.

\section{RESULTS AND DISCUSSION}

Table 1. PT Graduates Performance in the Licensure Examination

\begin{tabular}{|c|c|c|c|c|c|c|}
\hline \multirow{2}{*}{} & \multicolumn{2}{|c|}{ APK } & \multicolumn{2}{c|}{ MS } & \multicolumn{2}{c|}{ PT APPS } \\
\cline { 2 - 7 } & $F$ & $\%$ & $F$ & $\%$ & $F$ & $\%$ \\
\hline Above Passing & 22 & 15.17 & 21 & 14.48 & 18 & 12.41 \\
\hline Below Passing & 123 & 84.82 & 124 & 85.51 & 127 & 87.58 \\
\hline TOTAL & \multicolumn{7}{|c|}{145} \\
\hline $\begin{array}{c}\text { Average Institutional Passing } \\
\text { Percentage }\end{array}$ & \multicolumn{7}{|c|}{$\mathbf{2 1 . 6 9 \%}$} \\
\hline
\end{tabular}

Table 1 reveals the performance of one hundred forty-five graduates in Physical Therapy in the Licensure Exam from March 1999 - March 2012 in the three Board subjects which were broken down as follows: $30 \%$ for APK, $25 \%$ for MS and $45 \%$ for PT Apps, in all, a total of $100 \%$.

Slightly more than a tenth (12.41\%) passed the licensure examination among the 145 graduates.

Twenty-two (15.17\%) passed in the APK, twenty-one (14.48\%) passed in MS and eighteen (12.41\%) passed in PT Application.

Table II reflects the Academic Performance of PT graduates in the three Board Subjects namely: APK, MS and PT Apps.

In APK, majority (62.76\%) of the graduates was rated Fair, second in rank (28.28\%) got rating of Good, followed by those who got $(7.59 \%)$ rated Very Good, and the bottom of the rank (1.38\%) got Excellent.

In the MS, majority (61.38\%) belonged to the Good category. Second in rank got a rating of Fair (27.59\%). Third in rank got Very Good classification $(9.66 \%)$. The least number (1.38\%) got the Excellent rating. 
Table II. Academic Performance of PT Graduates in terms of their GPA

\begin{tabular}{|c|c|c|c|c|c|c|c|c|c|c|c|c|}
\hline \multirow{2}{*}{ GPA Rating } & \multicolumn{3}{|c|}{ APK } & \multicolumn{3}{|c|}{ MS } & \multicolumn{3}{|c|}{ PT APPS } & \multicolumn{3}{|c|}{ AVERAGE } \\
\hline & $\mathbf{F}$ & $\%$ & Rank & $\mathbf{F}$ & $\%$ & Rank & $\mathbf{F}$ & $\%$ & Rank & $\mathbf{F}$ & $\%$ & Rank \\
\hline $\begin{array}{c}\text { Excellent } \\
1.0-1.5\end{array}$ & 2 & 1.38 & 4 & 2 & 1.38 & 4 & 0 & 0.00 & 4 & 1 & 0.92 & 1 \\
\hline $\begin{array}{c}\text { Very Good } \\
1.6-2.0 \\
\end{array}$ & 11 & 7.59 & 3 & 14 & 9.66 & 3 & 15 & 10.34 & 3 & 13 & 9.20 & 3 \\
\hline $\begin{array}{c}\text { Good } \\
2.1-2.5 \\
\end{array}$ & 41 & 28.28 & 2 & 89 & 61.38 & 1 & 53 & 36.55 & 1 & 61 & 42.07 & 2 \\
\hline $\begin{array}{c}\text { Fair } \\
2.6-3.0\end{array}$ & 91 & 62.76 & 1 & 40 & 27.59 & 2 & 77 & 53.10 & 2 & 69 & 47.82 & 1 \\
\hline $\begin{array}{c}\text { Poor } \\
\text { below } 3.0\end{array}$ & 0 & 0.00 & 5 & 0 & 0.00 & 5 & 0 & 0.00 & 4 & 0 & 0.00 & 1 \\
\hline Sum & \multicolumn{3}{|c|}{370.48} & \multicolumn{3}{|c|}{344.86} & \multicolumn{3}{|c|}{364.37} & \multicolumn{3}{|c|}{359.9} \\
\hline Mean & \multicolumn{3}{|c|}{2.56} & \multicolumn{3}{|c|}{2.38} & \multicolumn{3}{|c|}{2.51} & \multicolumn{3}{|c|}{2.48} \\
\hline TOTAL & \multicolumn{3}{|c|}{145} & \multicolumn{3}{|c|}{145} & \multicolumn{3}{|c|}{145} & \multicolumn{3}{|c|}{145} \\
\hline
\end{tabular}

In the PT Apps., almost half (47.82\%) was ranked one who got the rating of Fair. Second in rank $(42.07 \%)$ was rated Good. Third in rank $(9.20 \%)$ was rated Very Good. No one got an Excellent category.

Table 3. Significant Correlation Between Licensure Examination Results and Academic Performance (GPA) in APK, MS and PT Apps.

\begin{tabular}{|c|c|c|c|c|c|}
\hline Board Subjects & df & $\mathbf{r}$ & $\begin{array}{c}\text { Critical Value } \\
\text { of } \mathbf{r}\end{array}$ & Interpretation & $\begin{array}{c}\text { Decision on } \\
\text { Hypothesis }\end{array}$ \\
\hline APK & 143 & -0.30203259 & 0.1946 & Significant & Reject \\
\hline MS & 143 & -0.464744615 & 0.1946 & Significant & Reject \\
\hline PT APPS & 143 & -0.475530686 & 0.1946 & Significant & Reject \\
\hline
\end{tabular}

Table 3 shows correlation between licensure examination results and academic performance (GPA) in APK, MS and PT Apps. When subjected to Pearson Product Moment Coefficient of Correlation test, the obtained correlation coefficient $r$ was (-) 0.30203259 which was higher than the critical value of 0.1946 at $143 \mathrm{df}$ and 0.05 level of significance. This means that academic performance is significant to licensure examination results. This significant correlation was further tested using t-test which obtained a t-value of 3.948 which is higher than the critical value of $t$ of 1.96 , thus, significant. This coincides with the study of Lengacher 
and Keller 1990 on Academic predictors of success on the NCLEX-RN examination for associate degree nursing students which revealed that GPA is one of the best predictors of success in such examination.

The same result came out with licensure examination and academic performance in MS. The computation was higher than the critical value of $r$ 0.1946 at $143 \mathrm{df}$ and at 0.05 level of significance; hence, it is significant. The rejection of the null hypothesis was validated when it was subjected to t-test. The outcome was a $t$ of 6.3396 which was much higher than the critical value of $t$ of 1.96 at $143 \mathrm{df}$ and at 0.05 level of significance; thus, significant.

Pertaining to PT Apps, the computation arrived at $r$ of (-) 0.475530686 which was higher than the critical value; thus, it is significant. When further tested using the t-test of significance which obtained a $t$ of 6.4457 which is higher than the critical value of $t$ of 1.96 at $143 \mathrm{df}$ and at 0.05 level of significance. This significant result showed that the higher the academic performance of students; the higher are the results of their licensure exam. This result coincides the study of Stewart et al, 2005 who found the significant relationships between licensure examination performance and academic performance.

\section{CONCLUSION}

Academic performance (GPA) was a predictor of licensure examination success. This was affirmed in the significant correlation between in the GPA of three board subjects and results of the licensure examination for PT.

\section{LITERATURE CITED}

Daley, L. K., Kirkpatrick, B. L., Frazier, S. K., Chung, M. L., \& Moser, D. K. (2003). Predictors of NCLEX-RN success in a baccalaureate nursing program as a foundation for remediation. Journal of Nursing Education, 42(9), 390-398.

Julian, E. R. (2005). Validity of the Medical College Admission Test for predicting medical school performance. Academic Medicine, 80(10), 910-917. Retrieved from http://goo.gl/wy63y2, (accessed last April 20, 2013).

Lengacher, C. A., \& Keller, R. (1990). Academic predictors of success on the NCLEXRN examination for associate degree nursing students. The Journal of nursing education, 29(4), 163-169. 
Ohtake PJ. (2010). Physical Therapy - Key Component of the Rehabilitation Team. Retrieved from http://goo.gl/w7Y88n, (accessed last April 20, 2013).

Schell, J. W. (2000). Think about Authentic Learning and Then Authentic Assessment. Using Authentic Assessment in Vocational Education. ERIC/ACVE Major Publications. Retrieved from http://goo.gl/nVSzD9 (accessed last April 20, 2013).

Stewart, C. M., Bates, R. E., \& Smith, G. E. (2005). Relationship between performance in dental school and performance on a dental licensure examination: an eight-year study. Journal of dental education, 69(8), 864-869. Retrieved from http://goo.gl/gkq7u7 (accessed last April 20, 2013).

Vendrely, A. M. (2007). An investigation of the relationships among academic performance, clinical performance, critical thinking, and success on the physical therapy licensure examination. Journal of allied health, 36(2), 108-123.

Thorndike, E. L. (1998). Animal intelligence: An experimental study of the associate processes in animals. American Psychologist, 53(10), 1125. Retrieved from http://goo.gl/8m9Hnt (accessed last April 22, 2013).

Thorndike, E. L. (1911). Edward Lee Thorndike. Anim. Intell, 1874, 1949. Retrieved from http://goo.gl/N24E8A, (accessed last April 20, 2013).

Weibell, C. J. (2011). Principles of learning: 7 principles to guide personalized, student-centered learning in the technology-enhanced, blended learning environment. 